\title{
STUDI KARAKTERISTIK PEMBENTUKAN UAP DALAM PEMBANGKIT UAP HELIKAL PADA REAKTOR MODULAR DAYA KECIL
}

\author{
Susyadi, Hendro Tjahjono, Sukmanto Dibyo, Jupiter S Pane \\ Pusat Teknologi dan Keselamatan Reaktor Nuklir-BATAN \\ Kawasan Puspiptek Gedung 80, Setu, Tangerang Selatan-15310 \\ email:susyadi@batan.go.id, telp:021-7560912,fax:021-7560913
}

Diterima editor: 8 April 2015

Direvisi editor: 27 April 2015

Disetujui untuk publikasi: 11 Mei 2015

\begin{abstract}
ABSTRAK
STUDI KARAKTERISTIK PEMBENTUKAN UAP DALAM PEMBANGKIT UAP HELIKAL PADA REAKTOR MODULAR DAYA KECIL. Reaktor modular daya kecil (SMR) sangat cocok untuk dibangun Indonesia, terutama pada lokasi-lokasi dengan kapasitas jaringan listrik yang rendah sehingga investigasi lebih jauh tentang reaktor ini sangat diperlukan. Umumnya SMR memiliki bentuk pembangkit uap yang kompak dan terintegrasi di dalam bejana tekan. Disain tersebut menyebabkan perbedaan pendekatan dalam memproduksi uap dibandingkan reaktor nuklir konvensional yang menggunakan pembangkit uap tabung-u terbalik. Oleh karena itu tujuan dari penelitian ini adalah untuk mengetahui karakteristik uap dan pola pembentukkannya di dalam pembangkit uap tipe helikal yang banyak digunakan oleh SMR. Metoda yang dipakai adalah dengan melakukan pemodelan dan perhitungan numerik menggunakan program RELAP5. Dalam pemodelan, aliran air umpan bertekanan dan temperatur rendah dimasukkan ke dalam tabung helikal sementara aliran fluida bertekanan dan temperatur tinggi, yang mewakili pendingin sistem primer reaktor, berada di sisi luar tabung. Hasil perhitungan menunjukkan bahwa uap yang dihasilkan oleh pembangkit uap helikal bersifat lewat jenuh yakni sekitar $25 \mathrm{~K}$ di atas titik jenuhnya. Hal ini memberikan keunggulan komparatif dari segi disain dan operasional pada SMR dibanding reaktor konvensional karena uap lewat jenuh yang dihasilkan dapat mengurangi kerugian turbin dan sekaligus meningkatkan efisiensi termodinamika.
\end{abstract}

Kata kunci: pembangkit uap helikal, SMR, PWR, uap lewat jenuh, RELAP5

\begin{abstract}
STUDY ON THE CHARACTERISTIC OF STEAM GENERATION IN HELICAL STEAM GENERATOR OF SMALL MODULAR REACTOR. Small modular reactor (SMR) is very suitable to be deployed in Indonesia especially for locations having low electrical grid capacity, so further investigation on the characteritic of this reactor is needed. In general SMR has a compact and integrated-to-vessel steam generator design. This design implies different approach in producing steam as compared to conventional nuclear power plant having inverted u-tube steam generator. For that reason, this research is intended to investigate the steam characteristic and how it is generated in the helical SG which is widely used in SMR. The method used is through numerical calculation of the SG model using RELAP5 code. In the model, the feed-water which has low pressure and temperature is flown into helical tubes while high pressure and temperatur fluid, which represents reactor primary system coolant, stays in outer side of the tube. Calculation result shows that the steam produced by helical steam generator is superheated, i.e. about $25 \mathrm{~K}$ above saturation temperature. This provides comparative advantage to SMR on the design and operational aspects compared to conventional reactors because the superheated steam it produces can reduce turbine losses and at the same time increase thermodynamic efficiency.
\end{abstract}

Keywords: helical steam generator, SMR, PWR, superheated steam, RELAP5 


\section{PENDAHULUAN}

Pembangkit uap (Steam Generator, SG) merupakan perangkat penghasil uap pada pembangkit listrik tenaga nuklir (PLTN) yang menerapkan siklus sistem konversi daya Rankine tak langsung. Dari yang saat ini beroperasi, umumnya bertipe cangkang dan tabung (shell and tubes) dimana aliran bertekanan dan bertemperatur tinggi untai primer dimasukkan ke dalam tabung tabung-u paralel yang terendam dalam air bertekanan rendah di sisi cangkang, sehingga uap terbentuk pada sisi tekanan rendah tersebut. Ada dua variasi disain yang banyak dipakai oleh reaktor konvensional saat ini yakni tipe tabung-u terbalik tegak (vertical inverted u-tubes) sebagaimana digunakan oleh reaktor AP1000 buatan Amerika Serikat[1], APR1400 buatan Korea Selatan[2, 3], ATMEA1 buatan Perancis[4], APWR buatan Jepang[5] dan tipe tabung-u rebah (horizontal u-tubes) sebagaimana dipakai oleh reaktor-reaktor buatan Rusia tipe VVER[6, 7]. Umumnya wujud SG tersebut sangat besar dan bahkan dapat melebihi ukuran bejana reaktornya.

Pada reaktor modular daya-kecil (small modular reactor/SMR) yang mengintegrasikan seluruh komponen utama sistem pembangkit uap ke dalam satu wadah bejana tekan, disain SG-nya sangat berbeda. Disini SG memerlukan penyesuaian, yakni ke bentuk yang lebih kompak agar dapat ditempatkan pada ruang yang terbatas di dalam bejana reaktor. Ada beberapa cara untuk hal ini sebagaimana diaplikasikan pada beberapa disain reaktor SMR, yakni (1) dengan pipa helikal vertikal yang melingkari seluruh bagian anulus bejana reaktor dengan radius lingkaran yang besar [8] dan (2) dengan pipa vertikal lurus dan disusun dalam beberapa kelompok unit [9] dan (3) pipa helikal vertikal yang dikelompokkan dalam beberapa kelompok unit yang memiliki lingkaran dengan radius kecil sehingga dalam satu bejana bisa terdapat $8-12$ unit SG [10-12]. Berbeda dengan reaktor besar, pada SG jenis ini uap terbentuk di dalam tabung. Aliran fluida panas dan bertekanan tinggi dari teras reaktor akan berada diluar tabung (sisi shell), sedangkan air umpan (feedwater) bertekanan rendah pada sisi sekunder dimasukkan ke dalam tabung untuk memproduksi uap di dalamnya. Beberapa tabung helikal dirangkai secara paralel dan uap disatukan pada ujung bawah dan atasnya. Disain yang berbeda ini akan menyebabkan perbedaan karakteristik dalam memproduksi uap, termasuk di dalamnya kemungkinan perbedaan respon saat terjadi transien maupun kecelakaan. Pada penelitian ini, dipelajari pola pembentukan uap di dalam SG helikal. Studi dilakukan dengan melakukan pemodelan dan perhitungan numerik menggunakan program RELAP5. Dalam pemodelan aliran air umpan yang bertekanan dan temperatur rendah dimasukkan ke dalam tabung helikal sementara aliran sistem primer reaktor bertekanan dan temperatur tinggi berada di luar tabung. Tujuan dari penelitian ini adalah untuk mengetahui karakteristik uap dan pola pembentukkannya di dalam pembangkit uap tipe helikal yang banyak digunakan oleh SMR. Dengan diperolehnya karakteristik uap diharapkan dapat diketahui keunggulan dari sistem reaktor yang menggunakan SG helikal dibandingkan dengan penggunaan SG konvensional (tabung-u terbalik). Mengingat reaktor yang menjadi fokus dalam penelitian ini masih dalam tahap pengembangan disain dimana masih dimungkinkan terjadinya perubahan dimensi perangkat dan parameter thermohidrolika lainnya, maka studi ini akan lebih memfokuskan pada aspek karakteristik kualitatif dari phenomena yang terjadi.

\section{DESKRIPSI SISTEM}

Steam Generator (SG) helikal yang menjadi bahasan pada makalah ini adalah SG yang dipakai oleh reaktor modular daya kecil sebagaimana diuraikan pada acuan [8]. SG pada reaktor ini dipilih mengingat disainnya sedang dalam tahap pengembangan dan sekarang dalam tahap validasi melalui ekperimen [13]. Secara skematis, sistem reaktor yang menggunakan SG tipe helikal dan bagaimana SG tersebut diposisikan dapat dilihat pada Gambar 1a. 


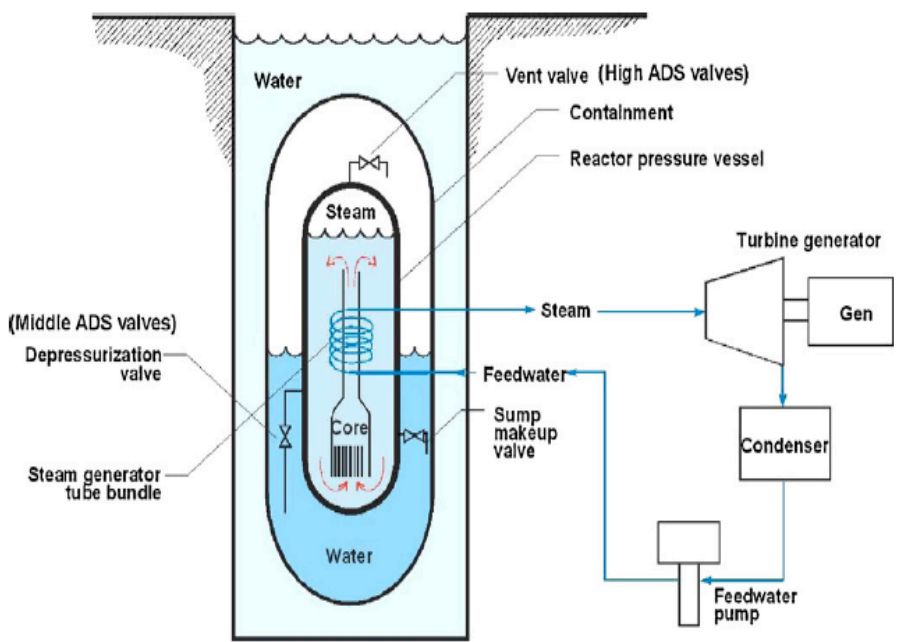

(a)

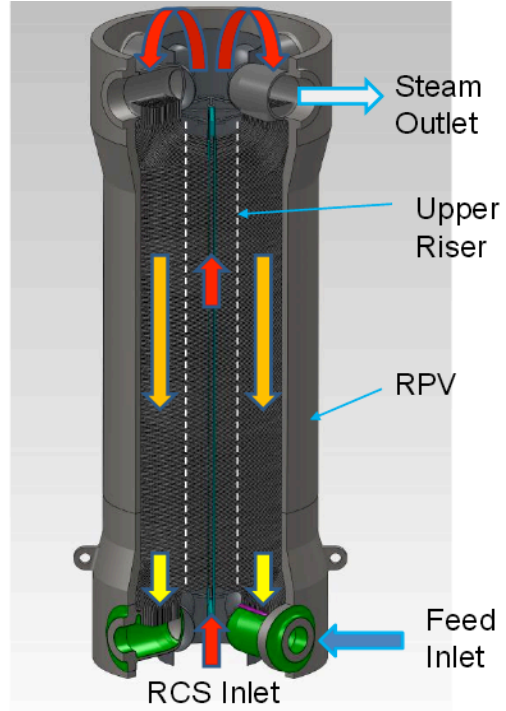

(b)

Gambar 1. (a) Sistem reaktor kecil modular [14] dan (b) disain SG helikal [15].

Sebagaimana terlihat pada Gambar 1a, pembangkit uap helikal terlihat melingkar di sekeliling anulus antara daerah-atas-teras (upper riser) dan bejana reaktor. Disisi sekunder, feedwater dimasukkan ke dalam tabung dari sisi bawah SG dan uap dihasilkan di dalamnya serta setelah itu dialirkan ke turbin. Total luas area perpindahan panasnya adalah sekitar $1624.2 \mathrm{~m}^{2}$ dengan panjang rata-rata tiap tabung sebesar $30.1 \mathrm{~m}$ [16] sehingga terdapat lebih dari 1300 tabung yang diparalel untuk membentuk dua SG yang saling tak bergantung satu sama lain. Wujud tampilan disain perangkat pembangkit uap dapat dilihat pada Gambar 1b. Adapun bagaimana tabung dililitkan di sekitar annulus bejana ditampilkan pada Gambar 2. Data geometri serta kondisi batas yang relevan untuk studi ini ditampilkan pada Tabel 1.
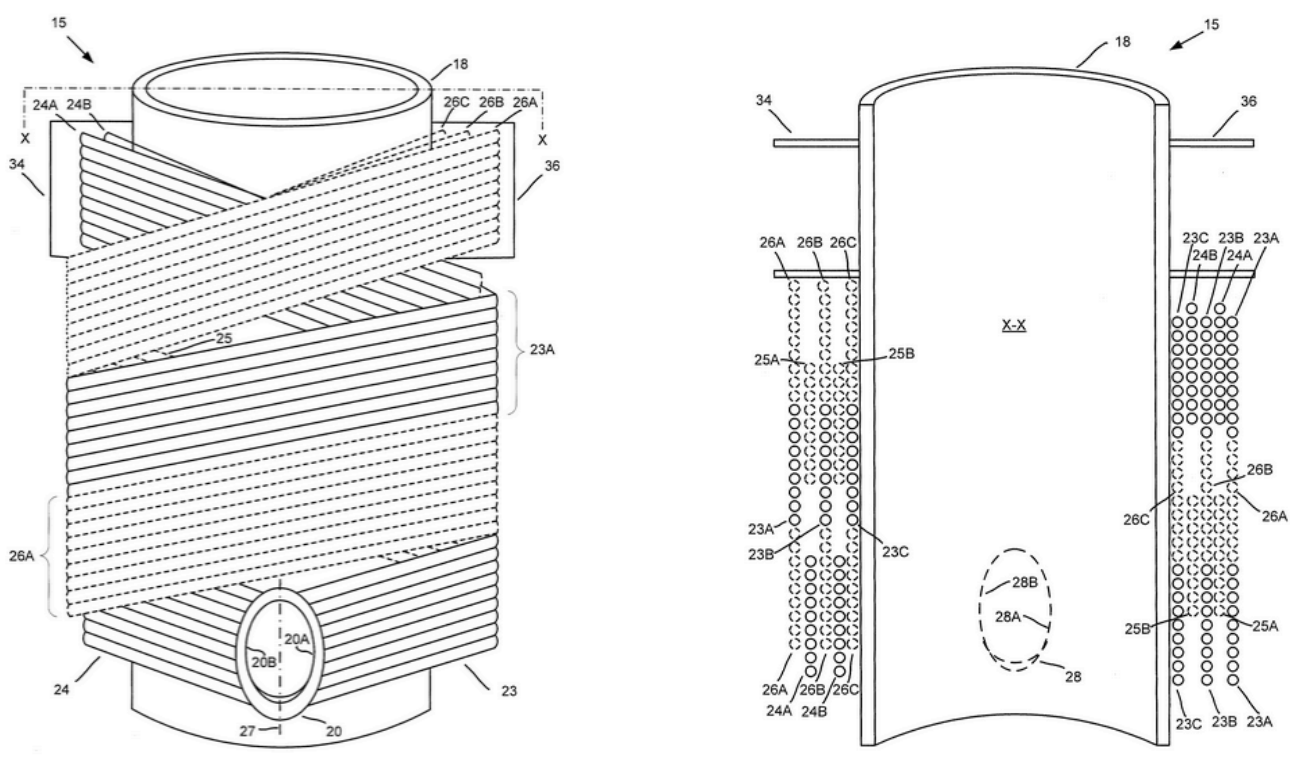

Gambar 2. Disain konfigurasi tabung pada pembangkit uap helikal [17]. 
Tabel 1. Data geometri SG helikal dan parameter perhitungan $[15,16,18,19]$.

\begin{tabular}{lc}
\hline Parameter & Nilai \\
\hline Luas perpindahan panas pada SG $\left(\mathrm{m}^{2}\right)$ & 1624.2 \\
Panjang rata-rata tabung $(\mathrm{m})$ & 30.1 \\
Diameter dalam tabung $(\mathrm{m})$ & 0.012573 \\
Diameter luar tabung $(\mathrm{m})$ & 0.015875 \\
Tekanan sisi sekunder $(\mathrm{MPa})$ & 3.1 \\
Temperatur air umpan ( K) & 422 \\
Laju alir air umpan $(\mathrm{kg} / \mathrm{detik})$ & 71.3 \\
Laju alir pendingin primer $(\mathrm{kg} / \mathrm{s})$ & 700 \\
Tekanan sistem primer $(\mathrm{MPa})$ & 12.7 \\
Temperatur sistem primer keluaran teras $(\mathrm{K})$ & 566 \\
\hline
\end{tabular}

\section{METODOLOGI}

Sebagaimana diungkapkan di pendahuluan, studi karakteristik pembangkit uap tipe helikal ini dilaksanakan menggunakan program RELAP5. Untuk dapat melakukan perhitungan maka bagian atas reaktor SMR yang mencakup SG perlu dimodelkan dulu ke dalam program. Sebagaimana terlihat pada Gambar 1, aliran air di sisi cangkang (shell) berasal dari keluaran teras yang naik ke atas melalui bagian riser dan kemudian bergerak secara radial ke samping bejana. Aliran ini merupakan fluida pendingin primer reaktor yang membawa energi fisi dari teras. Di wilayah SG, dimana tabung helikal berada, energi panas ini dipindahkan ke dalam fuida yang ada di dalam tabung. Uap akan dihasilkan di dalam tabung dan dikumpulkan jadi satu untuk kemudian diteruskan ke turbin. Pada kondisi tunak, sisi primer dan sekunder akan berada pada temperatur yang relatif tetap. Dari mekanisme tersebut, maka fenomena perpindahan panas di pembangkit uap dapat dimodelkan dalam RELAP5 dan nodalisasi berdasarkan uraian di atas dapat dilihat pada Gambar 3.

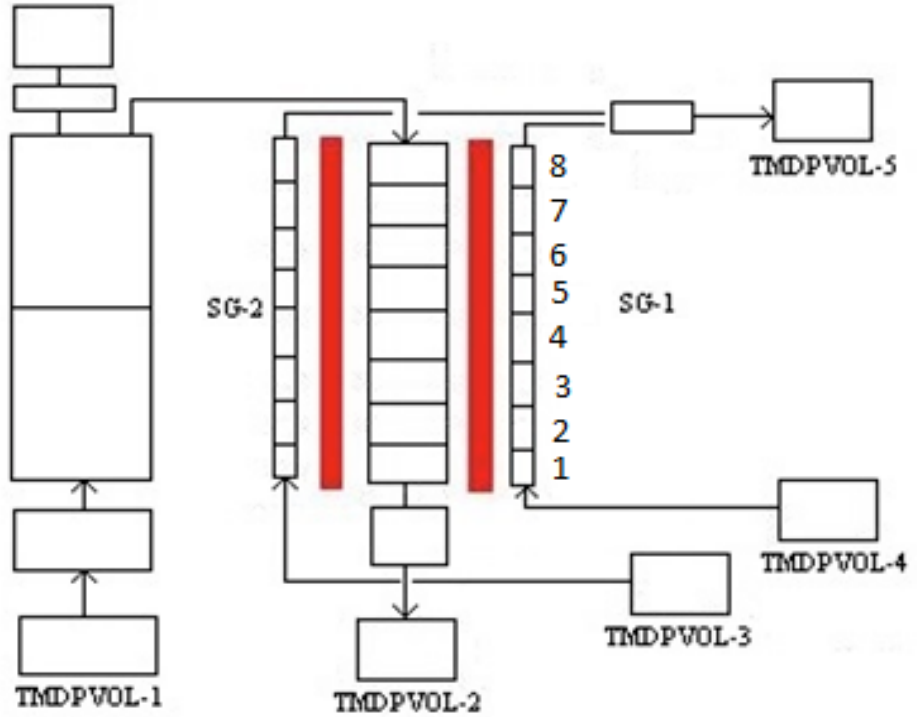

Gambar 3. Nodalisasi pembangkit uap helikal di SMR pada RELAP5. 
Secara umum model terdiri dari dua bagian yakni yang mewakili sisi primer dan yang mewakili sisi sekunder reaktor dan keduanya dibuat secara parsial. Sisi primer diwujudkan menggunakan beberapa model generik PIPE untuk mewakili bagian atas teras (riser) dan cangkang SG dan dua TMDPVOL yang bertindak sebagai kondisi batas (boundary condition). TMDPVOL-1 mewakili sumber aliran air panas yang keluar dari teras reaktor dan TMDPVOL-2 mewakili downcomer reaktor yang mengarah ke teras yang bertugas sebagai penampung aliran. Pada sisi sekunder, digunakan tiga TMDPVOL guna bertindak sebagai kondisi batas. Disisi ini, dimodelkan dua aliran air umpan untuk menyuplai dua pembangkit uap (diwakili oleh dua model generik PIPE) yang dimiliki oleh NuScale. Guna melihat lebih detil bagaimana pembentukan uap terjadi di dalam tabung maka model PIPE yang mewakili tabung SG dibagi menjadi 8 bagian yang sama panjang dimana penomoran volume dimulai dari bagian bawah. Sebagai sumber air umpan digunakan TMDPVOL-3 dan TMDPVOL-4, sedangkan untuk bagian turbin dimodelkan dengan TMDPVOL5. Guna melihat mekanisme perpindahan panas dari sisi primer ke sisi sekunder maka dua model generik HEAT STRUCTURE digunakan untuk mewakili dua SG yang ada.

\section{HASIL DAN PEMBAHASAN}

\section{Karakteristik uap pada kondisi tunak.}

Sebagai tahap awal studi, program RELAP5 dieksekusi hingga tercapai kondisi tunak dengan kondisi kerja sebagaimana diungkapkan pada Tabel 1. Hasil perhitungan sebagian ditampilkan pada Tabel 2. Pada tabel tersebut juga disertakan data karakteristik uap pada SG inverted u-tubes reaktor PWR konvensional sebagai pembanding.

Table 2. Hasil perhitungan karakteristik SG helikal dengan RELAP5.

\begin{tabular}{lcc}
\hline Parameter & $\begin{array}{c}\text { SG Helikal pada } \\
\text { SMR }\end{array}$ & $\begin{array}{c}\text { SG inverted } u \text {-tubes pada PWR 1000 } \\
\text { MWe [20, 21] }\end{array}$ \\
\hline Tekanan uap (MPa) & 3.1 & 7.626 \\
Temperatur saturasi (K) & 509.4 & 564.8 \\
Temperatur uap keluaran (K) & 535.2 & 564.8 \\
Laju alir uap (kg/s) & 71.3 & 1886.2 \\
Temperatur air umpan (K) & 422 & 499.8 \\
Daya ditransfer oleh SG (MWt) & 160 & 3415 \\
\hline
\end{tabular}

Tabel 2. menunjukkan bahwa uap yang dihasilkan oleh SG helical pada reaktor SMR bersifat lewat jenuh. Hal ini ditunjukkan oleh temperatur uap yang dihasilkan oleh keluaran SG sebesar $535.2 \mathrm{~K}$ yang berada lebih tinggi dari titik jenuhnya $\left(\mathrm{T}_{\text {sat }}=509.4 \mathrm{~K}\right)$. Karakteristik ini sangat berbeda bila dibandingkan dengan kondisi uap yang dihasilkan oleh SG inverted u-tubes reaktor konvensional sebagaimana ditampilkan pada kolom terakhir dari Tabel 2. Uap pada reaktor besar adalah bersifat jenuh dimana temperatur uap berada pada temperatur saturasinya. Kondisi uap yang lewat jenuh memiliki konsekwensi yang menguntungkan dari sisi disain dan operasional. Yang pertama adalah bahwa dengan kondisi lewat jenuh, maka tidak diperlukan lagi adanya pemisah uap dan pengering sebagaimana yang ada pada sistem SG reaktor besar dalam menghasilkan uap yang siap dikirim ke turbin. Hal ini karena uap lewat jenuh telah terbebas dari butir-butir air (droplets) dimana seluruh fluida telah berubah fase secara tuntas menjadi gas. Dengan demikian, maka SG dapat dibuat menjadi lebih kompak. Selain itu, dengan terjaminnya uap yang telah kering, maka sudu-sudu turbin menjadi relatif lebih aman dari kemungkinan mengalami kerusakan. Selama ini, turbin dapat mengalami kerusakan sebagai akibat dari ketidakseimbangan pada sudu-sudu yang berputar dengan kecepatan tinggi akibat keberadaan droplets yang menempel tidak merata. Selain itu, uap lewat jenuh juga memiliki lebih banyak energi yang dapat ditransfer menjadi gerak pada sudu-sudu turbin dibanding uap jenuh sehingga memiliki effisiensi termodinamika yang lebih baik. 
Tabel 2 juga menunjukkan bahwa tekanan dan temperatur kerja uap dari reaktor SMR lebih rendah dari yang dimiliki reaktor besar. Pada reaktor SMR, tekanan sekunder hanya kurang dari separuh tekanan sekunder reaktor PWR konvensional (3.1 MPa Vs 7.6 MPa). Selain itu temperaturnya juga di bawah temperatur kerja turbin PWR dengan perbedaan sebesar $499 \mathrm{~K}-422$ $\mathrm{K}=77 \mathrm{~K}$. Keadaan ini tentunya menguntungkan mengingat bila terjadi kecelakaan pecahnya pipa saluran uap menuju turbin, maka beban bagi sungkup pada reaktor SMR relatif lebih kecil dibanding pada reaktor besar. Dari segi disain, hal ini membuka peluang untuk dapat membuat sungkup yang ukurannya menjadi lebih kompak/kecil. Penjelasan di atas menunjukkan bahwa SG tipe helikal pada SMR memiliki keunggulan komparatif dibanding SG reaktor daya besar konvensional.

\section{Karakteristik pembentukan uap di dalam tabung SG helikal}

Untuk melihat lebih jauh karakteristik SG helikal, maka dilakukan analisis proses pembentukan uap di dalam tabung. Data hasil perhitungan RELAP5 ditampilkan sebagaimana pada Gambar 4.

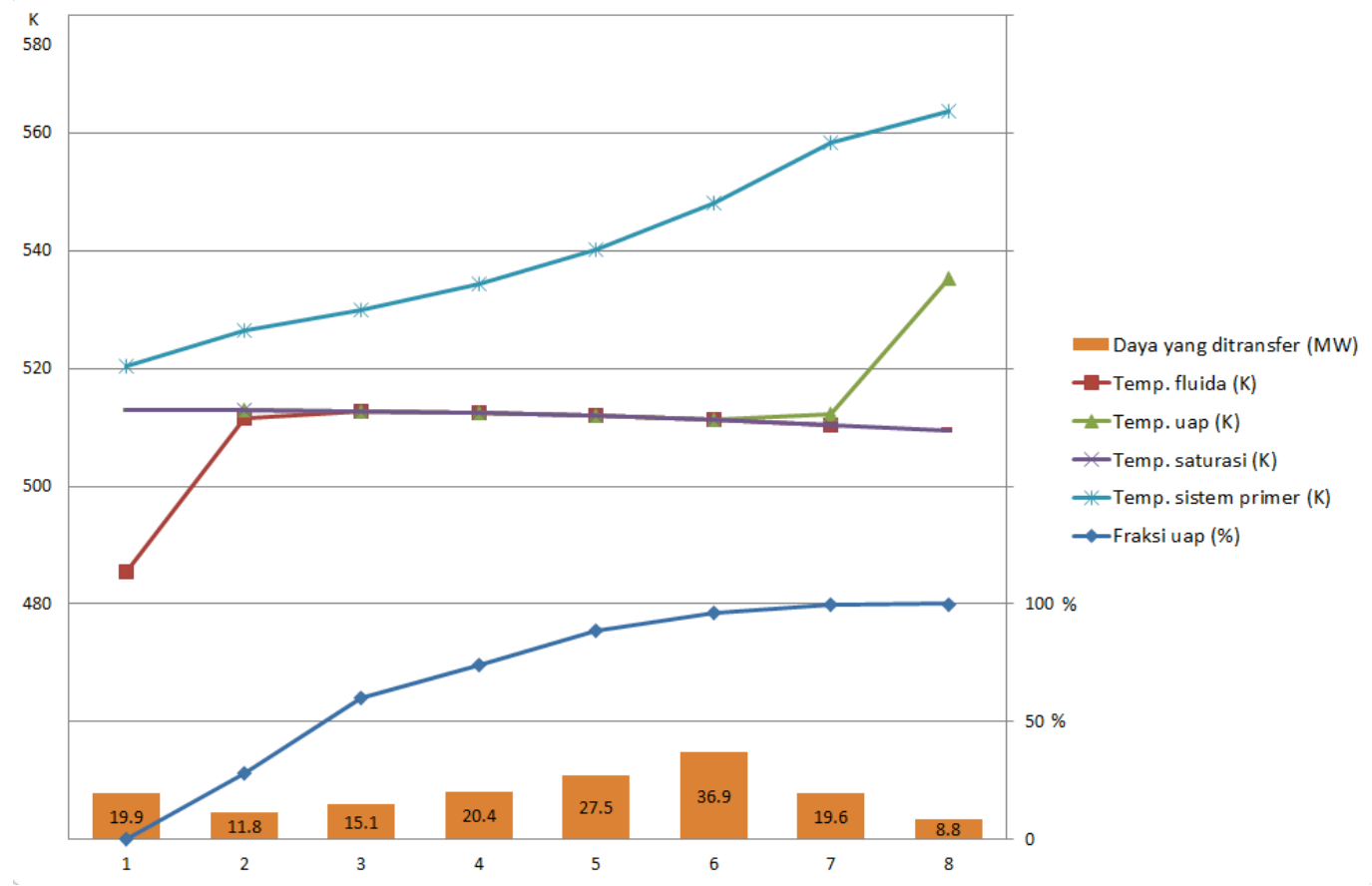

Gambar 4. Karakteristik pembentukan uap lewat jenuh di dalam tabung SG helikal.

Gambar 4 menunjukkan profil temperatur fluida pada sisi primer dan sisi sekunder SG di sepanjang wilayah aliran fluida. Selain itu juga ditampilkan nilai temperatur saturasi, fraksi uap di dalam tabung dan jumlah panas yang ditransfer pada tiap-tiap bagian volume. Gambar tersebut menunjukkan bahwa temperatur air umpan langsung meningkat pesat dari sejak memasuki wilayah pertama SG. Selanjutnya pada volume kedua, gelembung uap yang terbentuk mulai nampak namun belum signifikan jumlahnya. Dalam hal ini dapat kita simpulkan bahwa pada volume ini terjadi subcooled boiling karena temperaturnya masih di bawah titik jenuh. Selanjutnya, uap menjadi semakin banyak saat fluida memasukki volume ketiga dimana uap telah menempati ruang tabung lebih dari setengahnya (60.1\%). Secara bertahap uap semakin banyak terbentuk sejalan dengan mengalirnya fluida yang mengalami pemanasan sepanjang tabung. Pada dua volume bagian akhir (volume ke-7 dan ke-8), uap sudah mencapai lebih dari $99 \%$ dan masih mengalami penambahan panas dari sisi primer sehingga temperatur uap yang terbentuk lebih besar dari titik saturasinya. 
Terlihat juga bahwa temperatur keluaran uap mencapai $535 \mathrm{~K}$ atau sekitar $25 \mathrm{~K}$ lebih tinggi dari temperatur jenuhnya yang menunjukkan bahwa uap dalam kondisi kering dan terbebas dari butir air.

Pada diagram juga ditampilkan besarnya kalor yang dipindahkan pada masing masing volume. Dari sepanjang jalur aliran air umpan menjadi uap, perpindahan panas terbesar terjadi pada wilayah volume 6 . Hal ini konsisten dengan kejadian umum perpindahan panas dimana fase pendidihan sangat efektif dalam mengambil kalor di dalam suatu penukar kalor dibanding fase lain. Pada dasarnya pola perpindahan kalor pada setiap volume sebanding dengan perkalian antara perbedaan temperatur (antara sisi cangkang dan sisi tabung) dan koefisien perpindahan kalor global antar fluida di kedua sisi tersebut. Saat air umpan belum mendidih, kalor yang dipindahkan menurun dengan turunnya perbedaan temperatur antara air panas dan air umpan. Ketika air umpan sudah berada di daerah didih/jenuh, koefisien perpindahan kalor relatif tetap dengan nilai tinggi dan beda temperatur juga meningkat sehingga kalor yang dipindahkan juga meningkat sampai mencapai nilai maksimum pada beda temperatur tertinggi di daerah jenuh. Pada daerah lewat jenuh, koefisien perpindahan kalor relatif kecil dan perbedaan temperatur menurun sehingga kalor yang dipindahkan juga menurun sampai harga terendahnya di ujung paling atas dari tabung helikal.

Dari penjelasan tentang karakteristik uap dan pembentukaannya didalam tabung helikal dan perbandingannya dengan parameter SG konvensional, terlihat bahwa pola pembentukan uap pada SG helikal telah teridentifikasi dan menunjukkan keunggulan dari SG helikal dibanding SG konvensional tabung-u terbalik.

\section{KESIMPULAN}

Pada SG helikal dimana uap dihasilkan pada sisi dalam tabung karakteristik uapnya memiliki perbedaan dibanding pada SG konvensional tipe tabung-u terbalik. Hasil perhitungan menunjukkan bahwa uap yang terbentuk merupakan uap lewat jenuh dan kering dengan temperatur uap keluaran dari SG helikal mencapai $25 \mathrm{~K}$ di atas temperatur jenuhnya. Dari karakteristik uap yang diperoleh dapat ditunjukkan bahwa pembangkit uap tipe helikal pada SMR memiliki keunggulan komparatif dari segi desain dan operasional dibanding SG reaktor daya besar konvensional.

\section{UCAPAN TERIMA KASIH}

Rasa terima kasih yang sebesar-besarnya kami sampaikan kepada para peneliti dalam komunitas analisis keselamatan reaktor di Pusat Teknologi dan Keselamatan Reaktor Nuklir, khususnya terkait dengan analisis termohidrolika reaktor yang telah bersedia berdiskusi dan memberikan masukan yang berharga bagi kesempurnaan makalah ini.

\section{DAFTAR PUSTAKA}

1. Sutharshan, B., et al., The AP1000TM reactor: passive safety and modular design. Energy Procedia, 2011. 7: p. 293-302.

2. Kang, K.-H., et al., Experimental study on the blowdown load during the steam generator feedwater line break accident in the evolutionary pressurized water reactor. Annals of Nuclear Energy, 2011. 38(5): p. 953-963.

3. Abdoelatef, M.G., R.M. Field, and Y.-K. Lee, Thermodynamic Evaluation of Coupling APR1400 with a Thermal Desalination Plant. World Academy of Science, Engineering and Technology, International Journal of Chemical, Molecular, Nuclear, Materials and Metallurgical Engineering, 2015. 9(11): p. 1070-1078.

4. $\quad$ Tabuchi, K., et al., Concepts and Features of ATMEA1TM as the latest 1100 MWe-class 3Loop PWR Plant. Mitsubishi Heavy Industries Technical Review, 2009. 46(4): p. 8.

5. Suzuki, S., et al., Global Deployment Of Mitsubishi APWRr, A GenIII+ Solution To WorldWide Nuclear Renaissance. Nuclear Engineering and Technology, 2009. 41(8): p. 989-994. 
6. Chatterjee, B., et al., Analyses for VVER-1000/320 reactor for spectrum of break sizes along with SBO. Annals of Nuclear Energy, 2010. 37(3): p. 359-370.

7. Jabbari, M., et al., Power calculation of VVER-1000 reactor using a thermal method, applied to primary-secondary circuits. Annals of Nuclear Energy, 2015. 77: p. 129-132.

8. Reyes Jr, J.N., NuScale Plant Safety in Response to Extreme Events. Nuclear Technology, 2012. 178(2): p. 153-163.

9. Fetterman, R.J., et al. An overview of the westinghouse small modular reactor. in ASME 2011 Small Modular Reactors Symposium. 2011. American Society of Mechanical Engineers.

10. Chung, Y., et al., Development and assessment of system analysis code, TASS/SMR for integral reactor, SMART. Nuclear Engineering and Design, 2012. 244: p. 52-60.

11. Rowinski, M.K., T.J. White, and J. Zhao, Small and Medium sized Reactors (SMR): A review of technology. Renewable and Sustainable Energy Reviews, 2015. 44: p. 643-656.

12. Shirvan, K., P. Hejzlar, and M.S. Kazimi, The design of a compact integral medium size PWR. Nuclear Engineering and Design, 2012. 243: p. 393-403.

13. José N. Reyes, J., Development of Design Certification Test Programs, in ANS THD Technical Achievement Award Lecture2014.

14. Mascari, F., et al., Sensitivity analysis of the MASLWR helical coil steam generator using TRACE. Nuclear Engineering and Design, 2011. 241(4): p. 1137-1144.

15. Colbert, C., Overview of NuScale Design, in Technical Meeting on Technology Assessment of SMRs for Near-Term Deployment2013: Chengdu, China.

16. Reyes, J.N., Meeting Introduction and Overview of NuScale Design, 2009: Rockville, MD.

17. Williams, D.K., et al., Helical coil steam generator, 2014, Google Patents.

18. Reyes, J.N., Introduction to NuScale Design, 2008: Rockville, MD.

19. Atkinson, D., Overview of New Nuclear Technologies, in Joint Select Task Force on Nuclear Energy2014, Washington State Legislature: Washington.

20. Winters, J., R. Vijuk, and W. Cummins, AP1000 Design Control Document. Weistinghouse Electric Company LLC, Pittsbrugh, PA, US, 2004.

21. Shao, G. and X. Cao, Safety analysis of increase in heat removal from reactor coolant system with inadvertent operation of passive residual heat removal at no-load conditions. Nuclear Engineering and Technology, 2015. 47(4): p. 434-442. 